\title{
Defendiendo una frontera La ciudad de Corrientes, milicias e indios chaqueños, Siglos XVII-XVIII ${ }^{1}$
}

\author{
por Fernando Ariel Pozzaglio y Pedro Miguel Omar Svriz Wucherer
}

Abstract. - This article studies the frontier region of the Argentine city of Corrientes based on the concept of centre and periphery. It analyzes the level of autonomy this region obtained in all matters regarding its defense. The article focusses on the way local authorities, indigenous groups, Jesuits and citizens of Corrientes contributed to the defense of the border. One important group were the milicias guaranies, combat units consisting of indigenous who were considered indios amigos and therefore were allowed to carry weapons. Investigating on this microlevel local answers to problems concerning the interests of the monarchy, allows us a deeper insight into the general dynamics of peripheral territories, especially frontier regions and their practices.

\section{Analizando un microcosmos fronterizo: características e historiografía}

El Nordeste rioplatense era un territorio complejo y periférico de la monarquía hispana. El objetivo de este artículo consiste en estudiar esta región desde los conceptos de centro y periferia, para entender el grado de autonomía que alcanzaron estas tierras en cuanto a su defensa ${ }^{2}$. Como mencionan

1 Una primera versión de este trabajo fue presentado en el Congreso Internacional de Jóvenes Investigadores UAM. "Conectando" el Mundo Atlántico: redes, barreras e intercambio (1492-1830), organizado por la Universidad Autónoma de Madrid y celebrado en dicha ciudad entre los días 2 y 4 de abril de 2014. Los comentarios y sugerencias recibidos nos permitieron ampliar dicha ponencia al presente artículo, agradecemos especialmente los aportes del Dr. Bartolomé Yun Casalilla en este sentido.

2 Desde el punto de vista militar son numerosos los estudios recientes que han propuesto la descentralización de la defensa de fronteras en los imperios, a partir del análisis de las negociaciones e intereses que imperaban en cada uno de esos territorios. Entre estos tra- 
Amy Turner Bushnell y Jack P. Greene, esta autonomía de las periferias no sólo derivó de la debilidad de los recursos coercitivos de la metrópoli y la distancia del centro sino también del dominio de los colonos de las estructuras de autoridad a nivel local. Estas estructuras de autoridad surgieron del esfuerzo de los colonos para construir organizaciones políticas de estilo europeo en el Nuevo Mundo ${ }^{3}$. Si bien estos autores exponen estas ideas en relación a Gran Bretaña y sus colonias consideramos que esta configuración de la agency de los colonos, también puede aplicarse al imperio español ${ }^{4}$. Imperio que nos plantea una paradoja en la época moderna. Incrementa la concentración de poder en un centro cada vez más reducido, al mismo tiempo que crece su dependencia de las fuerzas sociales periféricas ${ }^{5}$. Para superar esta dicotomía, al historiador le resta, según Xavier Gil Pujol, "estudar o impacto do Estado moderno no microcosmo da vida local".

Nos centraremos entonces en un microcosmos del nordeste rioplatense, la ciudad de Corrientes, para entender cómo se produjo la interacción y negociación entre autoridades locales, parcialidades indígenas y jesuitas en la defensa de esta ciudad. Por medio de este caso, observaremos los mecanismos que utilizó la monarquía para defender este tipo de fronteras, dentro de los cuales las milicias ${ }^{7}$ fueron "un elemento central del ejercicio, reproducción y construcción del poder" al mismo tiempo que posibilitaron "la formación y difusión

bajos destacamos los de David Parrot, The Business of War. Military Enterprise and Military Revolution in Early Modern Europe (Cambridge 2012); y José Javier Ruiz Ibáñez, (ed.), Las milicias del rey de España. Sociedad, política e identidad en las Monarquías Ibéricas (Madrid 2009).

3 Amy Turner Bushnell/Jack P. Greene, "Peripheries, Centers, and the Construction of Early Modern American Empires. An Introduction": Christine Daniels/Michael V. Kennedy (eds.), Negotiated Empires. Centers and peripheries in the Americas, 1500-1820 (London 2002), pp. 1-14, aquí: p. 5.

4 Esta agency no será exclusiva de los colonos, también los pueblos indígenas de la región participarán con la suya propia en los procesos de negociación en esta frontera. Véase para el caso de los guaraníes Guillermo Wilde, Religión y poder en las misiones guaraníes (Buenos Aires 2009).

5 Véase esta idea en el artículo de Xavier Gil Pujol, "Centralismo e Localismo? Sobre as relaçoes políticas e culturais entre capital e territórios nas monarquías européias dos séculos XVI e XVII": Penélope. Fazer e Desfazer a História 6 (1991), pp. 119-144, aqui: p. 132.

6 Ibidem, p. 132.

7 Las milicias urbanas en Hispanoamérica eran formadas por pobladores que se congregaban para aventar un determinado peligro y que luego de la acción para la que fueron convocados, regresaban a sus hogares a continuar desempeñando sus tareas cotidianas. Las milicias no eran fuerzas rentadas, ni formaban una tropa permanente, estableciéndose de esta manera una clara separación entre el ejército estable y estas agrupaciones, que actúan coyunturalmente. Véase Marcela González, Las milicias, origen y organización durante la colonia (Córdoba 1995), p. 13. 
de la cultura política"8. De manera que conectaremos una historia local y regional con la política de la monarquía para este tipo de territorios periféricos. Siguiendo así los lineamientos de la connected history que Sanjai Subrahmayan propone para el estudio del imperio portugués en tierras asiáticas9.

Corrientes estaba situada en los límites de la región, representando una verdadera "periphery of the periphery" 10 en la gobernación de Buenos Aires (mapa $\mathrm{N}^{\circ} 2$ ). Esto significó, que frente a los ataques de los indios del Gran Chaco (guaycurues, payaguas, abipones, entre otros) los habitantes de Corrientes contaron, aparentemente, sólo con sus propios recursos para defenderse. El teniente de gobernador y el cabildo, máximas autoridades políticas de Corrientes, se encargaron de coordinar la movilización de vecinos y habitantes en las llamadas milicias urbanas. Actividad que cumplió un doble propósito: defender la ciudad ante los ataques $\mathrm{y}$, al mismo tiempo, reforzar la jerarquía y vínculos político-sociales entre sus habitantes. Estas milicias eran una verdadera manifestación del status social de cada individuo que las integraba ${ }^{11}$. Además de esas milicias urbanas, en las movilizaciones defensivas u ofensivas frente a los indios chaqueños, cumplieron un rol muy importante los denominados indios amigos. Estos indios actuaron como auxiliares de tropas españolas o "aliados" que combatieron en ocasiones sin la participación directa de soldados españoles ${ }^{12}$. Sin embargo, la magnitud de los ataques, la incapacidad de los habitantes de Corrientes u otros factores que estudiaremos, hicieron que en ciertas oportunidades las autoridades locales debieran solicitar el auxilio de indios armados de las reducciones jesuíticas cercanas, llamadas milicias guaranies. Esas movilizaciones causan una mayor complejidad en la explicación de la defensa de Corrientes, y nos obligan a establecer nuevos vínculos e intereses, incorporando los de los miembros de la Compañía de Jesús y sus indios reducidos, para y con dicha ciudad y región.

En este punto debemos señalar que la historiografía se ha preocupado por analizar las áreas poblacionales de la región (mapa $\mathrm{N}^{\circ} 2$ ), de forma por-

8 José Javier Ruiz Ibáñez, “Introducción: Las Milicias y el Rey de España”: Ruiz Ibañez, Las milicias (nota 2), pp. 9-38, aquí: p. 13.

9 Véase Sanjay Subrahmanyam, "Connected Histories. Notes towards a Reconfiguration of Early Modern Eurasia”: Modern Asian Studies $31: 3$ (1997), pp. 735-762.

${ }^{10}$ Nos referimos al trabajo de Mary Karasch, "The periphery of the Periphery? Vila Boa de Goiás, 1780-1835": Daniels/Kennedy (eds.), Negotiated Empires (nota 3), pp. 143-169.

${ }^{11}$ Numerosos estudios han abordado este carácter de las milicias urbanas en diversos ámbitos europeos y americanos. La citada obra de Ruiz Ibáñez, Las milicias (nota 2); reúne recientes contribuciones en este sentido.

${ }^{12}$ Cristophe Giudicelli, "Indios amigos" y movilización colonial en las fronteras americanas de la Monarquía católica (siglos XVI-XVII)": Ruiz Ibañez, Las milicias (nota 2), pp. 349-377, aquí: p. 349. 
menorizada pero desde nuestra perspectiva desconectadas entre sí. Sobre la historia de Corrientes encontramos estudios considerados clásicos como los de Manuel Mantilla y Hernán Gómez ${ }^{13}$, centrados principalmente en aspectos políticos, interés que también repercutió en la publicación de ciertas fuentes de la historia correntina en años posteriores ${ }^{14}$. Por su parte, Ernesto Maeder se centró en la economía virreinal de esta ciudad y su región, aunque su análisis se inicia en los siglos precedentes dándonos un panorama muy acabado del tema ${ }^{15}$. Sin duda estos estudios se complementaron con los análisis específicos dedicados a los pueblos de indios establecidos en el área correntina ${ }^{16}$, los cuales colaboraron permanentemente con mano de obra para la ciudad y que también permiten observar los intercambios de población nativa entre el área de Corrientes y los indígenas chaqueños. Se destacan los primeros estudios de Raúl de Labougle ${ }^{17}$, pero fueron los abordajes más recientes realizados por Teresa Cañedo Arguelles y María Laura Salinas, los que dieron una dimensión más precisa de las relaciones sociales y del trabajo indígena imperante en esos pueblos, y sus relaciones con los habitantes de Corrientes ${ }^{18}$. Para el caso de la reducción de Nuestra Señora de Itatí, Ernesto Maeder logró establecer comparaciones poblacionales con respecto a ciertas reducciones jesuíticas ${ }^{19}$, pero especialmente

${ }^{13}$ Véanse Manuel F. Mantilla, Crónica histórica de la Provincia de Corrientes, Tomo I (Buenos Aires 1928); y Hernán Gómez, Historia de la Provincia de Corrientes. Desde la fundación de la ciudad a la Revolución de Mayo (Corrientes 1929).

${ }^{14}$ Nos referimos especialmente a la publicación por la Academia Nacional de la Historia de Argentina, de las Actas capitulares de Corrientes (Buenos Aires 1941-1946) realizada en cuatro tomos y que abarca temporalmente desde 1588 hasta 1676.

${ }^{15}$ Ernesto J. Maeder, Historia económica de Corrientes en el periodo virreinal. 17761810 (Buenos Aires 1981).

${ }^{16}$ Estos pueblos de indios son Nuestra Señora de Itatí, Santiago Sánchez, Candelaria de Ohoma, Santa Lucía de los Astos y Santa Ana de los Guácaras.

17 Véanse de Raúl De Labougle, "La reducción franciscana de Candelaria de Ohoma": Revista de la Junta de Historia de Corrientes 3 (1968), pp. 7-14; "La reducción franciscana de Itatí": Investigaciones y Ensayos 3 (1968), pp. 281-323; "La reducción franciscana de Santa Lucía de los Astos": Investigaciones y Ensayos 5 (1968), pp. 131-152; y “La reducción franciscana de Santiago Sánchez": Investigaciones y Ensayos 8 (1970), pp. 123-153.

${ }^{18}$ Referimos a los trabajos de Teresa Cañedo Arguelles, La Provincia de Corrientes en los siglos XVI y XVII. Un modelo de colonización en el Alto Paraná (Madrid 1988) e idem, "La comunidad de Itatí, un marco para el debate cultural y la afirmación identitaria en el Paraná”: Revista Complutense de Historia de América 25 (1999), pp. 195-217; y de María Laura Salinas, Dominación colonial y trabajo indígena. Un estudio de la encomienda en Corrientes colonial (Asunción 2010).

${ }^{19}$ Ernesto J. A. Maeder, “Asimetría demográfica entre las reducciones franciscanas y jesuíticas de guaraníes": Revista Complutense de Historia de América 21 (1995), pp. 71-83. Itatí fue la única reducción franciscana establecida en tierras correntinas que estaba compuesta solamente por nativos guaraníes. 
destacamos la conservación y edición de documentos del cabildo indígena de Itatí, que permiten observar algunos aspectos de su vida cotidiana en el periodo tardocolonial, siendo un caso excepcional en la región ${ }^{20}$.

Por su parte, la historiografía dedicada a las reducciones jesuíticas ha sido muy profusa a lo largo de los años, sólo resaltaremos algunos de los más recientes dada la extensión del presente trabajo. Destacamos los aportes de Guillermo Wilde, quien analiza el proceso de etnogénesis producido en las reducciones ${ }^{21}$, o los respectivos estudios de Mercedes Avellaneda, Lía Quarleri y Martín Morales que han abordado las milicias guaraníes formadas en esas reducciones, y que nos son de gran ayuda para el presente análisis aunque centraran su atención principalmente en los conflictos con los portugueses provenientes del Brasil ${ }^{22}$. En contrapartida, el territorio chaqueño y sus habitantes ha sido objeto de una menor cantidad de estudios si los comparamos con las áreas precedentes. Sin duda el estudio de Beatriz Vitar es uno de los más importantes para comprender los conflictos y las acciones evangelizadoras en una frontera, aunque se centra en la región chaco-tucumana la cual posee características étnicas e históricas diferentes a la que abordamos en nuestro estudio ${ }^{23}$.

Dado este breve marco historiográfico, el presente trabajo persigue indagar sobre el rol que desempeñaron los diversos protagonistas de la defensa de Corrientes frente a los indios del Gran Chaco, sirviéndonos para establecer conexiones entre los diversos actores de estos territorios y profundizar en un aspecto un tanto olvidado por la historiografía que nos precede. Nos preguntamos hasta qué punto actuaron las milicias urbanas correntinas y las milicias guaraníes de las reducciones jesuíticas de forma

${ }^{20}$ Acuerdos del Viejo Cabildo de Itatí (Libros de Acuerdos Capitulares para los años 1799 a 1806, Cuentas de 1790 a 1797 y Libros de Acuerdos de 1812 a 1814). (Corrientes 1930).

${ }^{21}$ Wilde, Religión y poder (nota 4).

${ }^{22}$ Los estudios sobre milicias guaraníes han profundizado en sus acciones frente a los portugueses, dando la espalda a sus movilizaciones en la frontera chaqueña y sus vínculos con las ciudades de Corrientes y Asunción. Entre ellos, destacamos los de Mercedes Avellaneda, "El ejército guaraní en las reducciones jesuíticas del Paraguay": Revista História UNISINOS 9: 1 (2005), pp. 19-34; Mercedes Avellaneda/Lía Quarleri, "Las milicias guaraníes en el Paraguay y Río de la Plata. Alcances y limitaciones (1649-1756)": Estudos Ibero-Americanos 33: 1 (2007), pp. 109-132; Martín M. Morales, "Violencia en el paraíso": Manuel Marzal/Luis Bacigalupo (eds.), Los jesuitas y la modernidad en Iberoamérica. 1549-1773 (Lima 2007), pp. 387-420; Lía Quarleri, Rebelión y guerra en las fronteras del Plata. Guaranies, jesuitas e imperios coloniales (Buenos Aires 2009); y Martín M. Morales, "Violencia y misión en la antigua provincia del Paraguay": Studia Missionalia 60 (2011), pp. 1-20.

${ }^{23}$ Beatriz Vitar, Guerra y misiones en la frontera chaqueña del Tucumán (1700-1767) (Madrid 1997). 
diferenciada, tal como nos expone la historiografía de la región ${ }^{24}$. ¿Qué papel cumplieron cada una de las milicias en la defensa de Corrientes y en qué contextos actuaron cada una de ellas? Y entender ¿Cuál fue el rol que cumplieron las autoridades locales (teniente de gobernador y cabildo) en la relación entre ambos cuerpos armados?

Para contestar estas preguntas procederemos a conectar las relaciones dentro de esta frontera periférica y permeable, vinculando los intereses de vecinos y habitantes de Corrientes (Cabildo y milicia urbana), de los jesuitas y sus indios reducidos (milicias guaraníes), y de los indios del Gran Chaco. En un plano más amplio, se pretende saber en qué medida esas acciones militares que desarrollaron ambas milicias en Corrientes fueron informadas a las autoridades peninsulares y en qué forma lo hicieron las instituciones locales. Una extensa y variada documentación comunicaba ambas orillas del Atlántico (cartas, reales cédulas, informes, entre otros) durante los siglos XVII y XVIII. Esto significa vincular información de fuentes que guardan el Archivo General de Indias (Sevilla, España) con la del Archivo General de la Provincia de Corrientes (Corrientes, Argentina) y los fondos del Archivo General de la Nación (Buenos Aires, Argentina), para alcanzar a comprender la circulación de la información en este imperio ${ }^{25}$.

Este análisis desde el microcosmos de Corrientes hacia una comprensión de las fronteras periféricas de la monarquía nos permitirá avanzar de lo micro a lo macro, para lograr así entender los mecanismos y vinculaciones entre instituciones y protagonistas que participaron en la configuración de la defensa de una ciudad de la "periphery of the periphery".

\section{Corrientes, una ciudad en la frontera}

Un jesuita anónimo a mediados del siglo XVIII expresaba que la ciudad "(Corrientes) es aún más corta, y desostrada (sic) que la de Santa Fe y solo

${ }^{24}$ Los estudios de las milicias guaraníes (nota 22) no analizaron estas movilizaciones a la ciudad de Corrientes. De igual manera, los pocos trabajos sobre historia colonial de Corrientes destacaron el rol de las milicias urbanas pero no las acciones de las milicias guaraníes. Entre ellos véanse los citados trabajos de Manuel F. Mantilla, Crónica histórica (nota 13), Hernán Gómez, Historia de la Provincia (nota 13) y de Ernesto J. A. Maeder, Historia Económica (nota 15) e idem, "La guerra de fronteras y el reflujo de la conquista rioplatense en el siglo XVII": Boletín de la Academia Nacional de la Historia 60 (1987).

${ }^{25}$ Recientes trabajos han profundizado sobre la circulación de la información en el imperio hispano véase Arndt Brendecke, Imperio e información. Funciones del saber en el dominio colonial español (Madrid 2012). 
parece tiene el nombre de ciudad faltándole lo más que es el serlo"26, estas palabras brindan una idea inicial de las características que tiene la urbe que analizamos. La ciudad fue fundada el 3 de abril de 1588 por el adelantado Juan Torres de Vera y Aragón, en el margen izquierdo del río Paraná, cerca de la confluencia de este río con el río Paraguay, en una zona marginal de los dominios coloniales hispánicos. Esta ubicación marginal, tanto geográfica como geopolítica, condicionó, esencialmente, la escasez de recursos materiales con los que contó la ciudad correntina y, por ende, de su desarrollo económico durante gran parte de la época colonial. Inicialmente, los vecinos implementaron una agricultura de subsistencia en las chacras, unidades de producción rudimentarias, que se conformaron en los alrededores de la ciudad en virtud de las mercedes otorgadas por el fundador de la ciudad y los sucesivos gobernadores y sus tenientes. La producción agrícola, basada en los cultivos de maíz, trigo y algunos tubérculos, producto de la simbiosis entre la agricultura española e indígena, resultó siempre exigua y deficiente en una sociedad que se acostumbró a sufrir crisis cíclicas y hambrunas, tratando de subsanarse esta escasez mediante las políticas de cooperación entre los vecinos, ya sea obligando a vender a los dueños de chacras los excedentes de su cosechas a los pobladores más necesitados o mediante el repartimiento de indios encomendados, proveniente de los pueblos cercanos, para sumar mano de obra a las cosechas y siembras de las chacras de los correntinos no encomenderos.

Por otra parte, la ganadería, especialmente vacuna y caballar, constituyó otro rubro destacado en la economía correntina colonial. Dada la abundancia de los planteles de ganado vacuno que se diseminaron por la campaña de la jurisdicción hasta convertirse en cimarrones, los vecinos dispusieron de un recurso abundante y barato que, mediante el sistema de vaquerías, pudieron aprovechar. Esta economía depredadora trajo como consecuencia inevitablemente la continua disminución y posible aniquilación de los planteles de ganados vacunos de la jurisdicción. Pronto se dio la necesidad de establecer estancias en donde criar, reproducir y multiplicar el ganado vacuno para su consumo, la utilización de sus despieces y su eventual comercialización. Con el correr de los años del siglo XVIII, Corrientes ensanchó sus fronteras mediante el establecimiento de chacras y estancias en dirección sur y suroeste, logrando ocupar a fines del periodo colonial gran parte de la jurisdicción de la provincia que hoy constituye Corrientes. En el siguiente mapa podemos observar precisamente el avance de la frontera correntina a lo largo de los años:

${ }^{26}$ Archivo Histórico Nacional (en adelante AHN). Clero-Jesuitas, Leg. 120. "Descripción de la Provincia del Paraguay" (1761). f.1v. 
Mapa 1:“Expansión de las fronteras correntinas (1588-1810)"

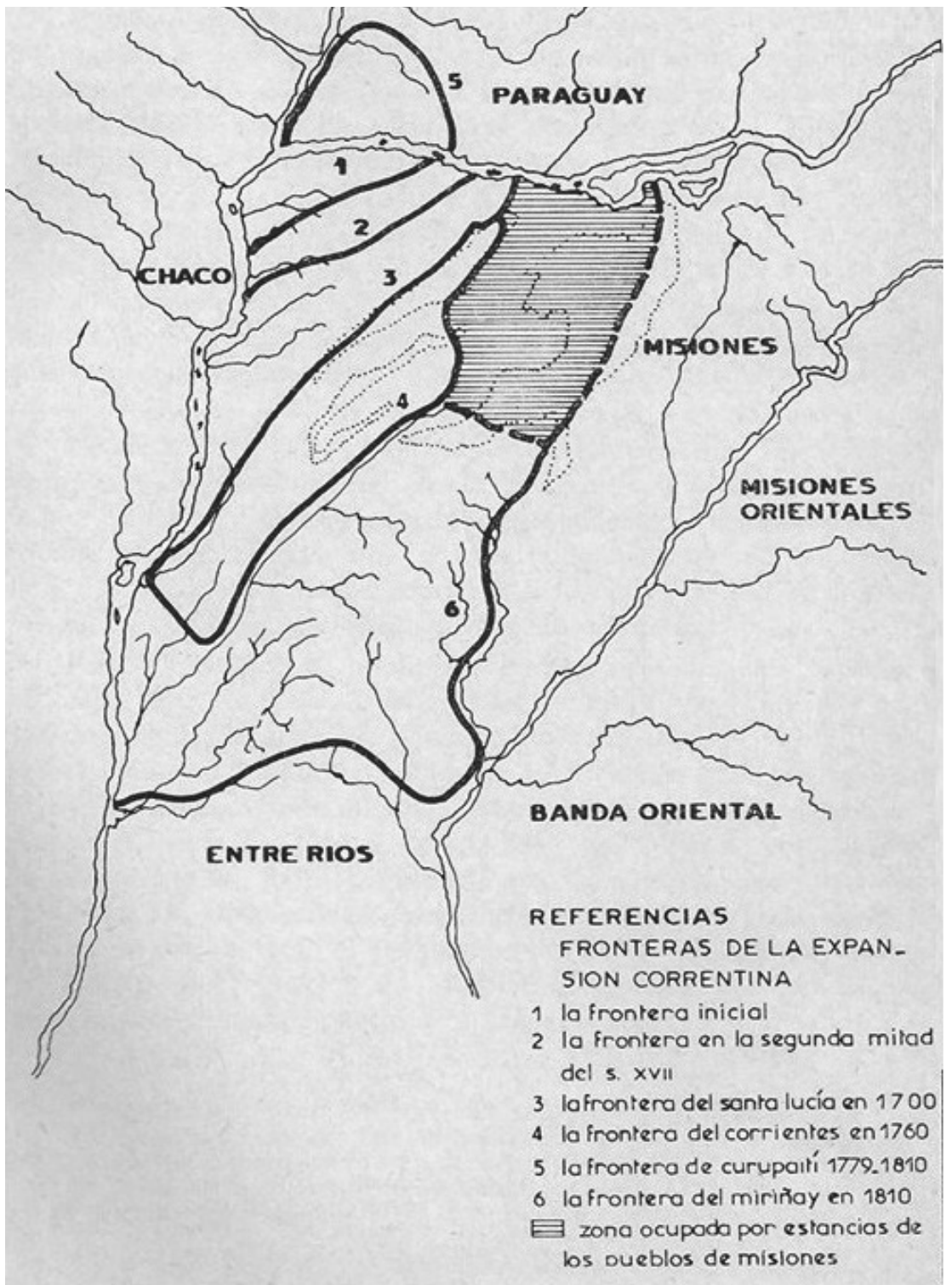

Selección propia. Fuente: Ernesto J. A. Maeder, Historia Económica (nota 15), pp. 98-99.

El aislamiento geopolítico señalado, sumado a que la ubicación de Corrientes se hallaba fuera del circuito de la plata del Potosí y a los intereses económicos 
de la corona hispánica, redundó en una pobreza estructural de sus vecinos que se acostumbraron a vivir con lo justo y necesario, y con las armas en las manos, en un espacio hostil y escaso de recursos materiales redituables a corto plazo. Una de las carencias más evidentes de la sociedad correntina colonial, al igual que el resto de las marginales ciudades del Río de la Plata, se manifestaba en la falta de circulante metálico, lo cual debió ser suplida por el establecimiento de los denominados frutos o "monedas de la tierra". Este sistema consistía en el intercambio o trueque de un producto por otro, estableciéndose previamente su valor nominal por medio de una tabla confeccionada por el cabildo. Por lo general, en un mercado interno rústico y pastoril como el de Corrientes fue común que se utilizara como medio de cambio el lienzo de algodón, la yerba e, incluso, el cuero vacuno.

Asimismo, otro de los obstáculos para el desarrollo económico de Corrientes colonial fue la falta de recursos, conocidos como propios y arbitrios con los cuales hacer frente a los gastos urbanos, como construcciones edilicias civiles y religiosas, refacción de espacios públicos, que se manifestaban cada vez más onerosos. Estos menesteres y aislamiento marcaron las características particulares de la ciudad correntina a lo largo de la época colonial, pese a la política implementada por el gobierno local, representado esencialmente por su cabildo y el teniente de gobernador ${ }^{27}$, tendientes a conseguir del gobierno superior y del monarca aportes y permisos legales para romper las trabas legales impuestas por la legislación y la estructura política y económica en donde se vio incluida, y llevar a Corrientes a una etapa más prospera.

Desde una mirada más regional, debemos decir que la ubicación geográfica de Corrientes tuvo desde su fundación como objetivo facilitar las comunicaciones por vía fluvial entre las ciudades de Santa Fe y Buenos Aires con la gobernación del Paraguay, cuya capital era Asunción. Al mismo tiempo se pretendía que Corrientes se comunicara por vía terrestre con las provincias del Tucumán, utilizando como nexo la ciudad de Concepción del Bermejo, situada en la región chaqueña. Sin embargo, esas conexiones fluviales y terrestres pretendidas por la monarquía entre las ciudades no pudieron llevarse a la práctica de forma efectiva. Las primeras décadas del siglo XVII mostraron la imposibilidad de desarrollar una fluida comunicación entre las ciudades del Nordeste rioplatense, principalmente

${ }^{27}$ Las funciones políticas, civiles, económicas y judiciales de ambas autoridades de la ciudad pueden verse sintetizadas en Hernán Gómez, Historia de la Provincia (nota 13) pp. 133-141. 
por dos motivos: la irrupción de los indígenas del Chaco desde el oeste y los avances bandeirantes desde el oriente. Ambos movimientos provocaron la relocalización de varios núcleos de población, generando modificaciones en la comunicación, administración y economía de estos territorios. La ciudad de Concepción del Bermejo en territorio chaqueño fue destruida por los indios guaycurúes en 1632 y sus habitantes debieron trasladarse a Corrientes. Por su parte las reducciones jesuíticas del Guayrá y Tapé fueron destruidas en su mayoría por los portugueses del Brasil, debiendo los jesuitas trasladar sus indios y algunas de sus misiones a las cercanías de los ríos Paraná y Uruguay. La destrucción de ciudades y reducciones junto a las movilizaciones de población, que también se dio en otras regiones americanas, hizo que esas primeras décadas del siglo XVII fuesen consideradas como de "crisis" e inclusive se alude a ellas como de "retroceso de la conquista" 28 .

Esa situación de crisis dejó a cada ciudad de la región con un área de influencia reducida y con una precaria comunicación político-comercial por medio de los ríos Paraguay y Paraná29. El eje que formaron Asunción, Corrientes, Santa $\mathrm{Fe}$ y Buenos Aires funcionó sólo en determinadas épocas del año y, especialmente, en los periodos que estas ciudades lograban una relativa paz con las parcialidades indígenas cercanas. En tiempos de guerra, esta conexión quedaba rota en alguno de sus tramos y los habitantes de cada ciudad buscaban sobrevivir con sus propios esfuerzos y recursos.

El mapa 2 expone las áreas de dominio que tenían las ciudades de origen hispano-criollo y las reducciones jesuíticas hacia el año 1700. Este mapa permite ver el aislamiento aparente en el cual se encontraban dichos núcleos poblacionales.

El estudio de las acciones de defensa de la ciudad de Corrientes en determinados periodos del siglo XVII y XVIII permitirá demostrar que este tipo de representaciones como el mapa $\mathrm{N}^{\circ} 2$ no expone cómo funcionaba la frontera en tiempos de conflicto. En esos instantes se movilizaban recursos $\mathrm{y}$ hombres en diversas direcciones y por medio de negociaciones que posibilitaron la supervivencia de las ciudades y sus habitantes.

${ }^{28}$ Ernesto J.A. Maeder. "La guerra de fronteras" (nota 24), p. 131.

${ }^{29}$ Un estudio sobre la navegación en estos ríos véase Rafael E. Velázquez, "Navegación Paraguaya en los siglos XVII y XVIII": Estudios Paraguayos 1:1 (1973), pp. 45-75. Un testimonio de este tipo de viajes véase en Pedro José de Parras, Diario y derrotero de sus viajes. 1749-1753. España - Río de la Plata - Córdoba - Paraguay (Buenos Aires 1943). 
Mapa 2: “Áreas de influencia de las ciudades y reducciones jesuíticas en el Nordeste Rioplatense hacia el 1700"

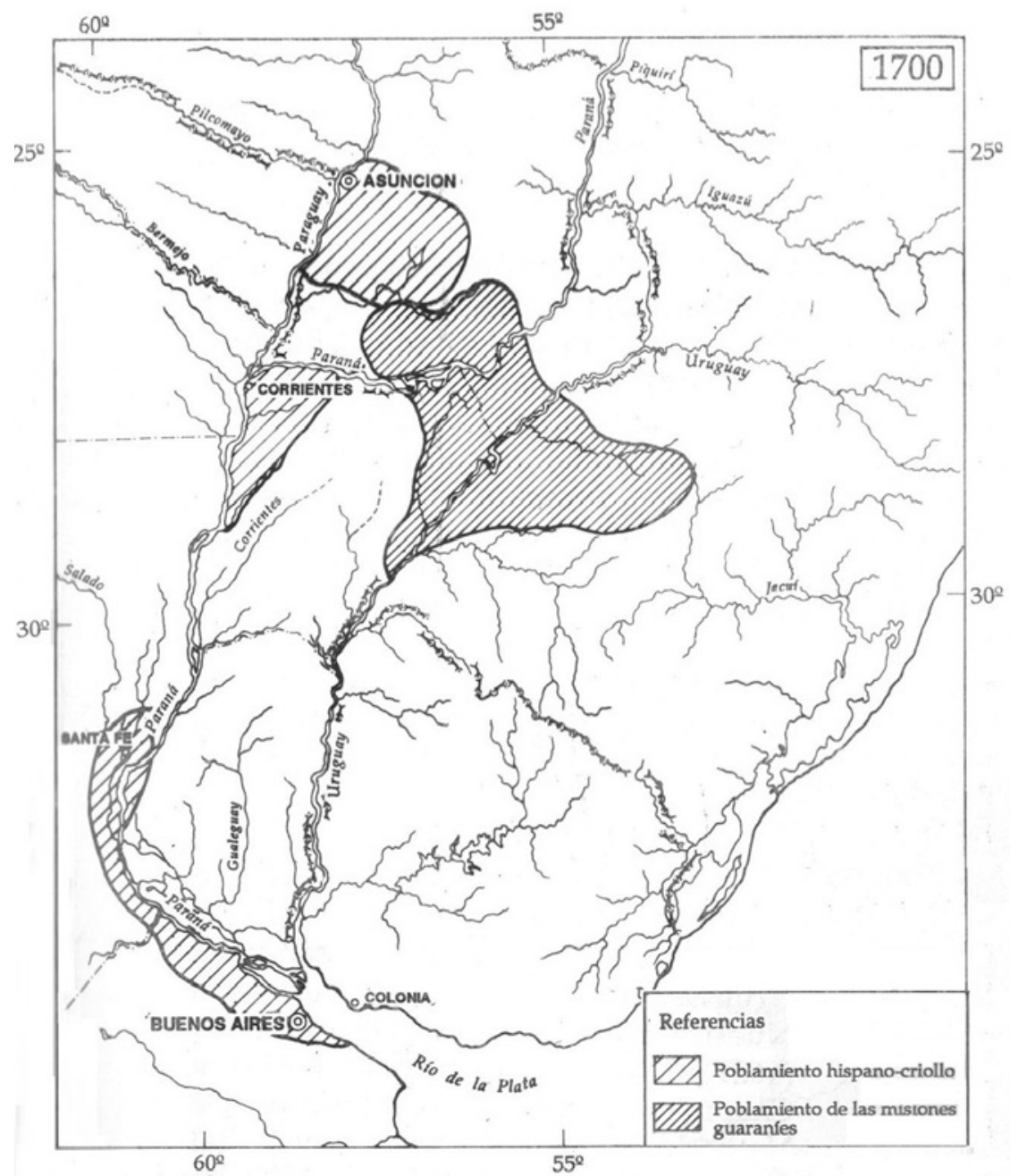

Fuente: Selección propia. Fuente: Ernesto J. A. Maeder/Ramón Gutiérrez, Atlas Histórico del Nordeste Argentino (Resistencia 1995), p. 59.

Esta negociación y lucha armada con indígenas no fue exclusiva del Nordeste rioplatense, por el contrario se repitió en otros ámbitos americanos en los cuales la defensa de la frontera era cotidiana. El norte de Nueva España o el sur del reino de Chile son los casos más conocidos para la América 
española ${ }^{30}$, pero también se dieron situaciones similares en el ámbito de las colonias pertenecientes a otros imperios europeos. Por ejemplo, estos enfrentamientos fueron constantes en el Brasil colonial, desde la Amazonia hasta Sao Paulo, donde se repitieron este tipo de luchas con indios que no lograban ser convertidos ${ }^{31}$. De forma similar se plantearon periodos de enfrentamiento de los colonos franceses e ingleses contra algunos grupos indígenas de América del norte. Semejante situación afrontaron los holandeses durante su dominio en algunas islas del Caribe, Pernambuco y Guayana (Surinam) ${ }^{32}$. La colonización en regiones de Asia ha demostrado que también allí la negociación entre nativos y colonizadores era frecuente para lograr la perdurabilidad de los enclaves coloniales ${ }^{33}$.

${ }^{30}$ Véanse por ejemplo Salvador Bernabeu Albert/Frédérique Langue (eds.), Fronteras y sensibilidades en las Américas (Madrid 2011); Juan Carlos Ruiz Guadalajara, "Capitán Miguel Caldera y la frontera chichimeca: entre el mestizo historiográfico y el soldado del rey": Revista de Indias 70:248 (2010), pp. 23-58; Salvador Bernabeu Albert (ed.), El Gran Norte Mexicano. Indios misioneros y pobladores entre el mito y la historia (Sevilla 2009); Philip Wayne Powell, Capitán mestizo. Miguel Caldera y la frontera norteña. La pacificación de los chichimecas (1548-1597) (México 1980); y Philip Wayne Powell, La guerra chichimeca (1550-1600) (México 1977).

Para el caso de Chile véanse Guillaume Boccara, "Notas acerca de los dispositivos de poder en la sociedad colonial-fronteriza, la Resistencia y la transculturación de los reche-mapuche del centro-sur de Chile (XVI-XVIII)": Revista de Indias 56 : 208 (1996), pp. 659-695; Rodrigo Moreno Jeria, Misiones en Chile Austral. Los jesuitas en Chiloé 1608-1768 (Sevilla 2007); y Jimena Obregón Iturra, “Aproximación crítica al pensamiento dicotómico "indios amigos" versus "indios enemigos" bajo el gobierno del Marqués de Baides, Chile, 16391646": Revista CUHSO 15:2 (2008), pp. 25-30.

${ }^{31}$ Véanse José Carlos Vilardaga, São Paulo na órbita do Império dos Felipes. Conexões castelhanas de uma vila da América portuguesa durante a união ibérica (1580-1640) (São Paulo 2010); Pedro Puntoni, O Estado do Brasil. Poder e politica na Bahia colonial (15481700) (São Paulo 2010); Fernando Rosas Moscoso, "Las fronteras de la fe y de las Coronas. Jesuitas españoles y portugueses en el Amazonas (siglos XVII-XVIII)": Marzal/Bacigalupo (eds.), Los jesuitas y la modernidad (nota 22), pp. 368-386; y Rafael Iván Chambouleyron, Portuguese colonization of the Amazon region, 1640-1706 (Cambridge 2005).

${ }^{32}$ Véanse Cornelio Ch. Goslinga, The Dutch in the Caribbean and on the Wild Coast, 1580-1680 (Assen 1971); y Cornelio Ch Goslinga, The Dutch in the Caribbean and in the Guianas, 1680-1791 (Assen 1985); y Ana Crespo Solana, América desde otra frontera. La Guayana holandesa (Surinam): 1680-1795 (Madrid 2006).

${ }^{33}$ Se destacan los trabajos de los Subaltern Studies que se focalizan en Asia a finales del siglo XIX. Entre ellos, Romain Bertrand, "La reencontré coloniale, une affaire de moeurs? L'arisocratie de Java face au pouvoir hollandais á la fin du xixe siécle": Genéses 43:2 (2001), pp. 35-52; y Romain Bertrand, "Les orientalistes, conseillers du prince colonial? Expertise savante et «politique musulmane» aux Indes Néerlandaises (c. 1880-1920)“: Raisons politiques $22: 2$ (2006), pp. 95-117. 
Por todas estas razones el caso de Corrientes permite crear un modelo aplicable a otras regiones del globo, lugares donde la colonización de los imperios se enfrentó a la necesidad de negociar con nativos locales ${ }^{34}$.

\section{¿Un "espacio en blanco"?: el Gran Chaco ${ }^{35}$}

El mapa $\mathrm{N}^{\circ} 2$, además de representar las áreas de influencia de los principales centros de población de la región, permite observar un espacio en blanco o vacío, el cual coincide en la forma en la cual se representó al Gran Chaco hasta bien avanzado el siglo XVIII. Esto se debió al poco éxito de los asentamientos hispanos en su interior y el reiterado fracaso de misiones evangelizadoras a ese territorio, que en conjunto hizo que los españoles llegaran a tejer historias legendarias sobre esas tierras y sus habitantes ${ }^{36}$; incluso este tipo de territorios comienzan a ser vinculados con el polisémico concepto de desierto ${ }^{37}$. Todos estos relatos contribuyeron a la erección de un espacio fronterizo en el cual los términos de infiel ${ }^{38} \mathrm{e}$ indio enemigo, se vincularon

${ }^{34}$ En esta cuestión de la negociación véase de Jean Paul Zuñiga (eds.), Negociar la obediencia. Autoridad y consentimiento en el Mundo Ibérico en la Edad Moderna (Granada 2013).

${ }^{35}$ El territorio del Gran Chaco es una de las regiones geográficas de Sudamérica que abarca los actuales territorios del norte argentino, Bolivia, Brasil y Paraguay. Geográficamente es una llanura que constituye un plano inclinado que se extiende a lo largo de 600 kilómetros, desde los 350 metros sobre el nivel del mar en los faldeos de las sierras del oeste argentino hasta los 50 metros en la falla de los ríos Paraná-Paraguay. Por tanto existen pocos cambios topográficos que producen alteraciones en el drenaje superficial y en las formaciones vegetales, marcando así diferencias en la ocupación del espacio y el uso del suelo. Maeder/Gutiérrez, Atlas Histórico (Fuente de la Mapa 2), pp. 20-23.

${ }^{36}$ Por ejemplo surge la leyenda de la Laguna de las Perlas que perdurará hasta finales del siglo XVIII, siendo de forma constante situada en regiones del Chaco que aún eran desconocidas para el español. Es decir este tipo de relatos fueron en gran medida propulsores de los intentos de conquistar esta región. Véase un análisis de esta leyenda en Marcos Altamirano, "La laguna de las perlas ¿Una leyenda impulsora de la conquista del Chaco?”: Actas de XXVIII ${ }^{\circ}$ Encuentro de Geohistoria Regional (2008), pp. 32-39.

${ }^{37} \mathrm{La}$ aplicación de una historia comparada entre diversos territorios americanos permite observar cómo este concepto se aplica a tierras tan dispares como la Patagonia, el Chaco, el sur de Buenos Aires o el Septentrión novohispano. Véase la evolución histórica de dicho concepto y su aplicación en ese último caso en Sara Ortelli, "Del despoblamiento a la aridez. El septentrión novohispano y la idea de desierto en la época colonial”: Dení Trejo Barajas (ed.), Los desiertos en la Historia de América. Una mirada multidisciplinaria (México 2011), pp. 18-23. Esta obra coordinada por Deni Trejo Barajas reúne una serie de trabajos en torno a este concepto que resaltan la polisemia del mismo y su aplicación a diversos contextos americanos.

${ }^{38}$ Este término debe entenderse también en un plano bidireccional, propio de la modernidad, tanto entendiendo a estos individuos en su relación con la corona hispánica como también en cuanto a su fidelidad religiosa. 
directamente a los de guaycurú y payaguá; y en contrapartida el de indio amigo o auxiliar se relacionó con el indio guaraní. De manera que la región en la cual confluyen los ríos Paraguay y Paraná se erigió para los colonos en una suerte de frontera entre lo civilizado y lo bárbaro. Esta dicotomía junto con la simplificación de las relaciones de lealtad, dejan de lado los interesantes matices que tiene esta región fronteriza, que presentó un funcionamiento diferente siendo totalmente porosa y permeable. Consideremos que en estos tiempos "la construcción de una "frontera" dista de ser lineal, y hay que acostumbrarse a tratar con objetos y categorías de contornos movedizos. Ni los indios amigos de hoy son los de mañana, ni los "amigos" de aquí son "amigos" en el mismo sentido"39. Esto nos sirve de gran ayuda a la hora de abordar el Gran Chaco, que presenta una gran variedad de grupos étnicos, y que en los testimonios de la época muchas veces fueron simplificados principalmente en tres grandes categorías: guaycurúes, payaguás y abipones ${ }^{40}$.

Por lo cual, cruzar el río Paraná hacia tierras chaqueñas significó para los habitantes de Corrientes, el encontrarse con grupos indígenas muy diversos, con rasgos propios y particularidades alejadas de las que hallaban entre los guaraníes, y que podemos sintetizarlas en tres puntos esenciales para contextualizar y comprender esta región:

- Grupos de indios con una cultura cazadora-recolectora, y por tanto con una movilidad estacionaria que cubría una gran extensión de tierra e impedía un contacto permanente y fluido con un mismo grupo;

- Diversidad de lenguas diferentes entre sí, lo cual conllevaba que el aprendizaje y los avances que pudieran producirse en una de ellas, no fuera aplicables a otras. Este aspecto queda muy claro en las dificultades de la labor evangelizadora en la región, para la cual el conocimiento de las lenguas nativas era fundamental.

- Los grupos de nativos chaqueños se conformaban por un número pequeño de miembros y no poseían un liderazgo que los aunara entre sí, o que fuera significativo y duradero, incluso en una misma etnia; esto impedía la posibilidad de negociar y/o pactar con líderes que facilitaran acuerdos y tratados entre los diversos actores de esta frontera.

${ }^{39}$ Véase Christophe Giudicelli. "Indios amigos" (nota 14), p. 350.

${ }^{40}$ Nos parece interesante señalar que el análisis de representaciones cartográficas del periodo colonial sobre el Gran Chaco puede mostrarnos este proceso de simplificación de categorías étnicas por parte de los contemporáneos. Contrasta cómo en el siglo XVI un sinnúmero de etnias "poblaban" el Gran Chaco, mientras que para la segunda mitad del siglo XVII las tres categorías de guaycurú, payaguá y abipón son constantemente repetidas para esta región. Véanse por ejemplo los dos tomos de Guillermo Furlong, Cartografía jesuítica del Río de La Plata (Buenos Aires 1936). 
Por lo cual las diferencias culturales, lingüísticas y socio-políticas entre los habitantes de una y otra orilla del río Paraná explican en gran medida el avance de la colonización y evangelización en un territorio, mientras se dieron sendos fracasos y numerosas dificultades para similares procesos en la otra orilla. No obstante, no se puede simplificar esta frontera, y negar los numerosos intercambios que se producían en la misma. Para tener un ejemplo claro sobre la permeabilidad de esta frontera, podemos remitirnos a la carta del 24.VII.1721 de Diego de los Reyes Balmaceda. En ella este gobernador del Paraguay se quejaba ante la corona de la alianza de paz que hizo su antecesor Juan Gregorio Bazán con los indios payaguás, dado que ello permitió que establecieran estos indios "sus tolderías en una isla que esta en medio del río arriba, cuatro leguas poco más o menos de esta ciudad (Asunción)". Y no sólo eso sino que según este testimonio, también se desplazaban los payaguás por la ciudad efectuando intercambios por los cuales obtenían preciados objetos. Narraba el gobernador que andaban estos indios:

“... con el motivo de rescate por esterillas de paja que hacen, pedacillos de cera que sacan de los montes y conchas, compraban cuñas, hachas, machetes y cuchillos de gente ignorante $[\ldots]$ con estas herramientas pasaba la introducción de ellos a casa de los herreros quienes les hacían mojarras y recatones de lanzas, terciados y casquilos (sic) de flechas con que en mas tiempo de año y medio se rehicieron de mejores armas que los españoles, que hasta sus macanas que eran de madera a forma de garrotes las llegaron a poner ruedas de bronce con puntas agudas en los remates que conseguían de los plateros y otras armas ofensivas ..."41.

Si bien es verdad que el gobernador Reyes Balmaceda persigue justificar una posible futura acción militar contra los payaguás ${ }^{42}$, su texto elaborado con otros objetivos nos expone las estrategias militares y económicas que tuvieron estos indígenas. Hacia esos mismos años los payaguás asolarán Corrientes con técnicas semejantes, mostrando un avance significativo hacia el sur en esos años. Claramente este tipo de testimonios nos posibilitan apreciar a esos indios no como sujetos pasivos que acataron las disposiciones reales sino como actores activos de este espacio fronterizo. En síntesis,

${ }^{41}$ AGI. Audiencia de Charcas, 216.

${ }^{42}$ En ese mismo año de 1721 el gobernador del Tucumán Esteban de Urizar solicitó a Reyes Balmaceda emprender una entrada conjunta al río Pilcomayo para facilitar las comunicaciones y comercio con el Perú. De las reducciones jesuíticas participaron 63 indios que fueron con algunos españoles en tres embarcaciones a realizar dicha labor, sin embargo la falta de coordinación entre ambas expediciones hizo que fuera un fracaso, fundamentalmente por el ataque constante de los payaguás. Este afán, que manifiesta en esta carta Reyes Balmaceda, de terminar con los ataques de los payaguás a Asunción se vio finalmente trunco porque finaliza al poco tiempo su rol como gobernador. Véase AGN. Sala VII. CAL. Legajo N².609. f.43v. 
debemos considerar que "no se trataba para colonos, administradores y misioneros de reproducir una realidad observada sino de integrarla en el esquema global de la sociedad que establecían en el mismo momento en que se apoderaban de sus elementos nombrándolos, otorgándoles un lugar preciso" ${ }^{\text {"33 }}$.

Por tanto la representación en blanco del Gran Chaco en la cartografía del periodo que estudiamos, responde a los reiterados fracasos que tuvo la colonización hispano-criolla en este territorio. El despoblamiento de la ciudad de Concepción del Bermejo y el posterior traslado de sus vecinos, habitantes y una porción de sus indios encomendados hacia Corrientes en 1632, significó que finalmente no se produjera otro asentamiento duradero en la región, se construyeron relatos legendarios sobre una tierra casi desconocida y se modificaron las relaciones entre los participantes de esta frontera. Además a mediados del siglo XVII algunos de los grupos de nativos que poblaban el Chaco adoptaron el caballo, teniendo modificaciones culturales significativas. Este animal les otorgó a los indios una mayor movilidad, adquirieron nuevas necesidades y un modo de combatir diferente que les permitió realizar en las ciudades y pueblos situados al otro lado del Paraná, veloces ataques que tuvieron por objeto el pillaje de armas y caballos, como también la captura de cautivos que comenzaron a ser desde entonces una moneda de cambio frecuente en este territorio fronterizo ${ }^{44}$.

\section{La defensa de la ciudad y sus protagonistas}

Corrientes, al igual que otras ciudades americanas, tenía "toda la vecindad asi de los vecinos que viven en ella, como de los que se mantienen esparcidos en sus campañas, divididos en diversos cuerpos de milicias como se acostumbró en Europa" ${ }^{\text {45. }}$. Esto significó que el teniente de gobernador y los miembros del Cabildo debieron negociar permanentemente con los posibles integrantes de las milicias para que cumplieran sus obligaciones. El servicio en las milicias, como en otras ciudades, incluía a hombres mayores entre catorce y sesenta años. Entre ellos, fueron los vecinos, especialmente los feudatarios, por el

${ }^{43}$ Christophe Giudicelli. "Historia de un equívoco. La traducción etnográfica de las clasificaciones coloniales. El caso neovizcaíno": Christophe Giudicelli (ed.), Fronteras movedizas. Clasificaciones coloniales y dinámicas socioculturales en las fronteras americanas (México 2010), pp. 139-171, aquí: p. 153.

${ }^{44}$ El comercio con cautivos por parte de los indios del Gran Chaco es un tema que aún debe profundizarse para entender la magnitud que tuvo el mismo, y poder compararlo con el desarrollado en otras regiones. Véase Fernando Operé, Historia de la frontera. El cautiverio en la América hispánica (Buenos Aires 2001).

${ }^{45}$ AHN. Clero-Jesuitas, Leg. 120. "Descripción de la Provincia del Paraguay" (1761). f.1v. 
título de encomienda que les distinguían, quienes tenían una mayor obligación en defender los territorios del rey con sus propias armas y caballos ${ }^{46}$. Un vecino de Corrientes explicaba este sistema a mediados del siglo XVIII:

“... costumbre es en esta ciudad tan antigua, como su misma fundación, que todos los que nacen en ella, y llegan a competente edad, para el manejo de las armas son precisados a servir con ellas al Rey nuestro señor y defender la tierra de tanto enemigo infiel que la combate el servicio lo hacen enteramente a su costa con sus propias armas, municiones, víveres, y caballos, sin que la falta alguna de estas cosas le sirva de disculpas para el cumplimiento de esta obligación derivada de los primeros fundadores como V.S. lo habrá experimentado; antes es ya obligación de los primeros padres de proveer de todo estos precisos avíos a sus hijos cuando llegan a competente edad".

Además, este vecino aclaraba que una mala situación económica personal no exceptuaba del servicio en las milicias:

“... por los que por su pobreza no alcanzan a hacerlo se obligan los hijos adquirir lo propios que le fructifica su personal trabajo sin que por esa queden sus padres desobligados del servicio que lo hacen igualmente con sus hijos hasta que su avanzada edad lo imposibilita, o dejan la obligación con la vida"47

Todas esas disposiciones teóricas quedaban en la práctica casi sin efecto en una tierra de frontera como Corrientes. Donde, como en otras partes del imperio, la obligación de servir al rey pasaba también por los intereses individuales que pudieran defenderse. La negociación cotidiana entre autoridades, vecinos y habitantes de la ciudad fue lo que permitió que cumplieran con sus obligaciones estas milicias. Exención de impuestos, facilidades para obtener tierras y/o la obtención de indios para nuevas encomiendas eran algunos de los métodos utilizados para lograr una activa participación en las milicias urbanas. Además, los milicianos lograban un reconocimiento social por participar en campañas militares que fueran exitosas, o incluso podían obtener algún cargo militar por su desempeño en el campo de batalla. Todo esto reforzaba la jerarquía social y status de cada individuo, al mismo tiempo que permitía un mejor posicionamiento para aquellos que no pertenecían a la élite de Corrientes ${ }^{48}$.

${ }^{46}$ Véase este tipo de obligaciones de los encomenderos y sus funciones militares en Günter Kahle, "La Encomienda como Institución Militar en la América Hispánica Colonial»: Anuario Colombiano de Historia Social y de la Cultura 9 (1979).

${ }^{47}$ Archivo General de la Nación, Buenos Aires, Argentina (en adelante AGN). Sala VII. Colección Andrés Lamas. Leg. $\mathrm{N}^{\circ} 7$. "Sediciones de los comuneros de Corrientes. Originales y copias" (1766-1767). f.14.

${ }^{48}$ Debe señalarse que los individuos que lograban en el sector hispánico de la sociedad, en este caso la élite de Corrientes, alcanzar cierta prominencia o posición "[...] se convertía de alguna manera en noble, a sus propios ojos y a los del resto." Esta idea de "distinción o 
La vida en la campaña de la mayor parte de los habitantes de Corrientes hizo difícil los recuentos de armas y hombres cuando no se contemplaban movimientos concretos que significaran beneficios para los integrantes de las milicias. Por ejemplo los miembros del Cabildo en 1648 intentaron realizar una reseña de armas porque ".... a mucho tiempo que no se ase [...] y nesesita saverse las que ay que gente y que munisiones para poner y dar el remedio que fuere necesario ..." ${ }^{49}$. Pero este tipo de convocatorias fracasaban. Los miembros de estas milicias no vieron factible el trasladarse hacia la ciudad abandonando sus tareas agro-ganaderas sólo para ser contabilizados y sin obtener algún tipo de rédito o beneficio.

Por tal motivo, la estrategia de las autoridades de Corrientes se modificó con el paso del tiempo. Se estableció la conveniencia que la revista de tropas coincidiera con ciertas celebraciones religiosas que obligaban a los habitantes de Corrientes a reunirse para reforzar lazos sociales. Fiestas de Patronos o la celebración de la Pascua de Resurrección ${ }^{50}$, fueron los momentos oportunos para contabilizar los milicianos. Pero en situaciones de emergencia, los tenientes de gobernador recurrieron a bandos para convocar estas reseñas en el menor tiempo posible. Francisco de Noguera Salguero proclamó un bando en 13.I.1723 para formar las milicias ante los ataques de los indios payaguás:

“... toda la gente de la jurisdicción de esta dha ciudad esta divertida por sus estancias y pagos y para reconocer la que hay, y distribuirla ordenadamente ordeno y mando q[ue] [...] sobre dhos vecinos [...] armas desde edad de catorce [...] para arriba comparezcan [...] en las compañías que les tocaren el día veinte y cuatro del corriente deste año que sea signal [sic] para celebrar reseña general en que se harán de listas reconocimiento de sus armas, y cantidad de gente que hubiere para los efectos de reforzar las compañías, y escuadras desta guarnición ..." ${ }^{5_{1}}$.

nobleza" jugó un papel fundamental en la discusión sobre la posición social de los individuos en la América colonial. Véase James Lockhart. “Organización y cambio social en la América española colonial": Leslie Bethell (ed.), Historia de América Latina. América Latina colonial: población, sociedad y cultura, tomo 4 (Barcelona 1990), pp. 63-108, aquí: p. 67.

${ }_{49}$ Academia Nacional de la Historia, Actas Capitulares de Corrientes. Tomo I (Buenos Aires 1941), p. 71.

${ }^{50}$ Esta celebración no tiene una fecha fija, se realiza entre el 22 de marzo y el 25 de abril. Véase Martín Alonso, Enciclopedia del Idioma, Tomo III (Madrid 1958), p. 3164; Hernán Gómez, Historia de la Provincia (nota 13), pp. 42-43. Un estudio sobre las fiestas religiosas en Corrientes y la participación del cabildo en su organización y desarrollo. Véase Fernando A. Pozzaglio, Las celebraciones religiosas en Corrientes durante los últimos años de la época colonial (2011).

${ }^{51}$ Archivo General de la Provincia de Corrientes (en adelante AGPC). Documentos de Gobierno (en adelante DG). $N^{\circ} 23$ (1720-1723). f. 177-177v. 
Incluso este bando establecía sanciones para los que no cumplieran con dicha disposición: “... cincuenta pesos aplicados mitad Cámara de $\mathrm{Su}$ Majestad y gastos de guerra, y de un mes de cárcel en la pública de esta ciudad ..." ${ }^{52}$. Estas disposiciones de castigo ante el incumplimiento son frecuentes en las convocatorias urgentes de milicias, al menos en los documentos. Desconocemos su grado de aplicación, pero probablemente fueran estrategias de negociación como el otorgamiento de mercedes, cargos o encomiendas, las que obtuvieran mejor resultados y adhesiones entre los posibles milicianos. Sin embargo en ciertas ocasiones la negociación fracasaba. Las promesas de las autoridades no fueron suficientes cuando las movilizaciones eran a tierras lejanas como Santa Fe y Buenos Aires, o cuando se asignaban turnos de guardia en un distante fuerte por un tiempo prolongado (dos meses o más). Esas situaciones generaron desobediencias en las convocatorias. El capitán Pedro Gribeo, el 14.VII.1726 decía:

“... que muchas personas han falta[do] y faltan a hacer las semanas de turnos que le toca hacer a cada uno en la guardia y presidios en que están destinados porque hacen ausencia sin mi licencia ni de la de los cabos yéndose [...] con pretexto de que van a conchabarse con los que tienen faenas de sebo y grasa para su manutención y a la otra parte del Uruguay y río Negro y porque esta totalmente prohibido el que salgan a hacer semejantes faenas sin expresa licencia ..." ${ }^{53}$.

Este tipo de desobediencias, en cambio, no se observa en las convocatorias para defender la propia ciudad de Corrientes. En esas oportunidades los vecinos y habitantes de Corrientes no oponían resistencia dado que defendían sus propios intereses (tierras, ganados, etc.). Además el servicio de milicia era más liviano en la ciudad cerca del hogar, y sólo cubrían guardias y "cárcel pública" 54 . Por tanto, los intereses de los vecinos de Corrientes marcaban en muchas oportunidades la viabilidad o factibilidad de algunas acciones militares dentro o fuera de la ciudad. Por ello algunas entradas a territorio chaqueño generaron poca oposición en los milicianos dado que las consideraban como oportunidades para obtener grandes beneficios. Sin embargo, muchas de esas entradas de castigo a lo largo de los siglos XVII y primeras décadas del XVIII fracasaban porque los recursos humanos y materiales eran escasos y por la imposibilidad de atacar directamente a los indios,

${ }^{52}$ AGPC. DG. N 23 (1720-1723). f. 177v.

${ }^{53}$ AGPC. DG. $N^{\circ} 24$ (1723-1730). f. 77. También pueden leerse en los Documentos de Gobierno de aquellos años las frecuentes deserciones en las milicias. Véanse los casos de Ramón de Céspedes y Diego Farina por ejemplo, quienes huyen con ropas, armas y municiones, y se solicita la rápida captura de cada uno. AGPC. DG. N 26 (1734-1742). f. 19-. f. $19 \mathrm{v} ;$ f. $32-$. f. $32 \mathrm{v}$.

${ }^{54}$ Ernesto J. A. Maeder, Historia Económica (nota 15), pp. 160-161. 
quienes huían sin presentar batallas en la espesura de los bosques chaqueños o en la planicie mesopotámica, frustrando los avances ${ }^{55}$. Se lograban obtener ciertos beneficios para la ciudad y sus habitantes, pero eran pocos en comparación con los recursos necesarios para cada una de esas entradas.

Los constantes ataques de los indígenas del Gran Chaco a Corrientes y la escasez de recursos de esta ciudad, sumados al fracaso de las entradas a territorio chaqueño y la negativa de sus milicianos a movilizarse lejos de la ciudad sin obtener grandes beneficios, fueron factores que ocasionaron el cambio de una estrategia ofensiva a una más defensiva por parte de las autoridades de Corrientes. En este sentido, optaron dichas autoridades por dos medidas en las cuales los nativos de una y otra orilla del Paraná fueron los principales protagonistas: entablar acuerdos amistosos con las parcialidades que amenazaban la ciudad; y fundar fuertes en lugares estratégicos del territorio por medio de la mano de obra indígena.

Los acuerdos con los grupos indígenas infieles fueron ciertamente más sencillos pero peligrosos para la seguridad de la ciudad. Los infieles en ocasiones se dirigían a Corrientes con el objetivo de intercambiar productos, pero muchas veces fueron estrategias para obtener materiales que mejoraran su armamento. Los payaguás ${ }^{56}$ por ejemplo aprovecharon tanto en Corrientes como en Asunción los acuerdos comerciales con los habitantes de esas ciudades para mejorar sus armas. A cambio los indios daban cautivas que capturaban, o también productos que alcanzaban por el intercambio con otros nativos, principalmente los guaycurúes ${ }^{57}$.

“... con dha paz han estado peltrechándose [sic] de cuñas, machetes y cuchillos que se les han dado por el rescate de algunas cautivas cristianas e infieles fuera de la herramienta que se les ha mandado aserar [sic] y componer en esta ciudad, y lo que

${ }_{55}$ Academia Nacional de la Historia, Actas Capitulares (nota 49), p. 423.

${ }^{56}$ Grupo de indios semi-nómada pertenecientes a la familia lingüística guaycurú que utilizaron los ríos Paraná y Paraguay para realizar intercambios y alianzas con diversas ciudades, como también feroces ataques en los siglos XVII y XVIII. Véase Francismar Alex Lopes de Carvalho, "Os "Senhores dos ríos" e suas alianças políticas": AIBR. Revista de Antropología Iberoamericana 42 (2005); Chiara Vangelista, "Los Payaguá entre Asunción y Cuiabá. Formación y decadencia de una frontera indígena (1719-1790)": Pilar García Jordán/Miquel Izard et al. (eds.), Conquista y resistencia en la historia de América (Barcelona 1991), pp. 151-165; y Bárbara Ganson, "Contacto intercultural. Un estudio de los payaguaes del Paraguay, 1528-1870”: Suplemento Antropológico 24 (1989), pp. 79-121.

${ }^{57}$ Los miembros del Cabildo de Asunción escribían el 1.XII.1704 que suponen que los payaguas tenían alianza con los guaycurús porque "an traido p.r rason de rescate como son plumas de avestruces pieles de venados cubiertos de serdas de cavallos i potrillos y dardos con casquillos de aspas de venados que son cosas que ellos no usan[...]". Materiales vinculados a los indios del Gran Chaco. Véase Archivo General de Indias (en adelante AGI), Charcas, 216. f.1v. 
ocultamente han rescatado dhos enemigos, cosa tan dañosa para nosotros. Porque con las cuñas hacen sus dardos macanas, arcos y flechas que son las armas de su uso y sacan la miel de las abejas y hacen la leña con dhas cuñas, y los cuchillos en astan para yerros de lanza con que hacen muchísimo daño a esta provincia ..."58.

Por esta situación, el teniente de gobernador Diego Martínez de Irala dice ante el Cabildo, “... que es publico y notorio [que] estamos en grandísimo riesgo y no tenemos defensa ninguna donde podemos fortificar si los indios se alsasen y rebelasen desde que en esta ciudad ay al presente indios ...”. La presencia de indios infieles en la ciudad y la falta de fuertes cercanos que inquietaban a las autoridades.

Esta inquietud en las autoridades llevó a que la solicitud de establecer fuertes en la frontera fuera reiterada en distintas oportunidades por los procuradores generales a la largo del siglo XVII ${ }^{59}$. Se construyeron algunos con materiales precarios y escasamente pertrechados para mediados de siglo, buscando acompañar la expansión hacia el suroeste, pero tuvieron escaso éxito y perdurabilidad ${ }^{60}$. En las primeras décadas del siglo XVIII nuevamente la idea de fundar fuertes toma fuerza para prevenir los ataques de los payaguás. Quienes asolaban la región en esos años. Baltasar García Ros escribe el 26.II.1723 que:

“... [la] experiencia lo muestra el Paraguay Santa Fe y Tucumán de no haber ejemplar hayan acometido los indios a semejantes fuertes por crecido que sea el número de ellos y los del Paraguay los he visto muchas veces y quien los guarda y defiende son dos o tres hombres que nunca faltan y esto en llegando embarcación pueden acusar al pueblo inmediato que podrá ponerse a dos leguas poco mas o menos distante de la costa para que los socorra con carne y alguna otra cosa que tuvieren y necesitaren y los juzgo defendidos de estos indios respecto de que van a pie y no se atreverán a internar tierra adentro ..."

Sin embargo, la escasez de recursos hizo que los habitantes de Corrientes no pudieran solventar el establecimiento de varios fuertes para defenderse. No bastaba con construir los fuertes, había que dotarlos de hombres y de recursos de forma permanente para que fueran efectivos, y además los vecinos y habitantes de Corrientes no estaban dispuestos a permanecer dos o más meses en un fuerte lejano de la ciudad y sus actividades.

${ }^{58}$ Carta de Francisco de Ledesma Valderrama. Asunción, 4.II.1676. AGI, Buenos Aires, 152A. f.1-f.1v. Obsérvese la estrecha similitud de estrategias utilizadas por los payaguás años más tarde en la citada carta del gobernador Reyes Balmaceda del 24.VII.1721 (nota 44).

${ }_{59}$ Academia Nacional de la Historia, Actas Capitulares (nota 14), pp. 282 y 407.

${ }^{60}$ Ibidem, pp. 207-208.

${ }^{61}$ AGPC. DG. $N^{\circ} 23$ (1720-1723). f. 189v. 
Entonces las autoridades buscaron alternativas para defender la ciudad frente a los ataques indígenas. Finalmente fueron los jesuitas y sus milicias guaraníes quienes defendieron Corrientes en situaciones puntuales, pero demostraron tener también sus propios intereses.

\section{Las milicias guaraníes entran en Corrientes: intervenciones y movilizaciones}

Las milicias guaraníes fueron cuerpos de indios armados que se formaron en las reducciones jesuíticas del Paraguay entre 1630 y 1641 con el objetivo de defenderlas de los ataques bandeirantes provenientes desde el Brasil ${ }^{62}$. Estas milicias tuvieron características propias, un entrenamiento constante y alcanzaron gran eficacia en sus movilizaciones, logrando detener el avance portugués. Todo ello significó que la Corona reconociera a estas milicias como cuerpos armados encargados de la defensa de esa frontera (1649) y además permitió el uso de armas de fuego a los guaraníes.

Al mismo tiempo que dieron estas prerrogativas a los jesuitas y sus reducciones, estos adquirieron nuevas responsabilidades en nombre del monarca. Debían estas milicias cumplir no sólo con la defensa de sus misiones sino también con los pedidos de los gobernadores de Buenos Aires y del Paraguay para defender sus territorios. En la práctica, la negociación entre autoridades locales, gobernadores y jesuitas fue constante para lograr que las milicias cumplieran con dicha obligación.

${ }^{62}$ Las bandeiras paulistas fueron las encargadas de realizar incursiones hacia el interior brasileño en búsqueda de mano de obra esclava indígena principalmente para las plantaciones de azúcar del litoral; estos avances pronto confrontaron con los pueblos de indios fundados por los jesuitas en el Guayrá, y posteriormente en el Tapé, provocando el abandono de muchas reducciones y la relocalización de las que lograron sobrevivir en territorios próximos a los ríos Paraná y Uruguay. Un testimonio de este proceso y sus consecuencias entre los nativos de las reducciones véase en Antonio Ruiz de Montoya, La conquista espiritual del Paraguay. Hecha por los Religiosos de la Compañia de Jesús en las Provincias de Paraguay, Paraná, Uruguay y Tapé [1639] (Rosario 1989). La historiografía dedicada a la interacción en esta frontera entre los imperios hispano y portugués ha sido variada y amplia, destacamos el trabajo de Francisco Bethencourt quien expone las conexiones que existían entre las coronas lusitana y castellana, incluso antes de la unión monárquica, y formula el concepto de Iberian Atlantic y su perdurabilidad hasta el siglo XVIII. Véase Francisco Bethencourt, "The Iberian Atlantic. Ties, Networks, and Boundaries": Lisa Vollendorf/Harald Braun (eds.), Theorising the Ibero-American Atlantic (Leiden 2013). pp. 15-36. Se destacan otros como John Manuel Monteiro, Negros da Terra. Índios e bandeirantes nas origens de Sao Paulo (São Paulo, 1994) que analisa el processo de esclavitud indígena llevado a cabo por los portugueses; Wilde, Religión y poder (nota 4), en el cual se aborda la etnogénesis guaraní en esta región; y Quarlei, Rebelión y guerra (nota 22) que aborda los problemas de límites y la guerra guaranítica producidos en la segunda mitad del siglo XVIII. 
Fue así que entre 1637 y 1735, la gobernación de Buenos Aires solicitó el servicio de los indios de las reducciones en 41 oportunidades, implicando un total de 38.798 indios. Para ese mismo periodo, la gobernación del Paraguay pidió a las reducciones 6.993 indios en 28 solicitudes $^{63}$. En estas cifras se incluyen las diferentes acciones que cumplían estas milicias. Entradas en tierras de infieles; enfrentamientos armados con europeos, principalmente portugueses; construcción de fuertes; escoltas de gobernadores; reparación de infraestructura y movimientos de tropas para defender esas urbes de un posible ataque; son las principales actividades que llevaron a cabo estas milicias que respondieron a una multiplicidad de tareas según las necesidades de los gobernadores. La tabla 1 establece cuántos de los indios movilizados desde las reducciones a la gobernación de Buenos Aires, tuvieron como destino la ciudad de Corrientes y/o pueblos de su jurisdicción para cumplir sus labores.

\section{Tabla 1:“"Las milicias guaraníes en la jurisdicción de Corrientes"64}

\begin{tabular}{l|l|l|l}
\hline Año & $\begin{array}{l}\text { Número de guaraníes } \\
\text { Movilizados }\end{array}$ & Indios atacantes & Lugar de destino \\
\hline 1637 & $\begin{array}{l}263 \\
(20 \text { embarcaciones })\end{array}$ & Caracarás y cupesalos & $\begin{array}{l}\text { Pueblo de Santa Lucía y } \\
\text { Corrientes amenazada }\end{array}$ \\
\hline $1638-1639$ & $\begin{array}{l}100 \text { españoles y } \\
230 \text { indios } \\
\text { (5 embarcaciones) }\end{array}$ & $\begin{array}{l}\text { Caracarás, capesalos, } \\
\text { mepenes y algunos } \\
\text { gualquilarós }\end{array}$ & $\begin{array}{l}\text { Corrientes y el pueblo } \\
\text { de Santa Lucía }\end{array}$ \\
\hline
\end{tabular}

${ }^{63}$ AGN. Colección Andrés Lamas. Leg. N 2.609. "Información y certificación acerca de varios puntos pertenecientes a los Indios Guaranis, mandadas hazer por el Padre Jayme de Aguilar Provincial de estas Provincias del Paraguay, Tucumán y Río de la Plata, y hechas por los Pp. s mas condecorados y experimentados de estas Missiones de Paraná y Uruguay" (02.XII.1735). f.44.

${ }^{64}$ Elaboración propia. Fuentes: AGN. Sala VII. Colección Andrés Lamas. Leg. N ${ }^{\circ}$ 2609. "Relación sumaria de los especiales servicios que los Indios Guaraní han hecho a S.M en los Gobiernos de Buenos Aires y Paraguay" (s/fecha ni autor). f. 405v; f. 406-f. 407; "Memorial de Jerónimo Herrán de la Compañía de Jesús, procurador general por la provincia del Paraguay, a Su Majestad" (21.I.1726): Pablo Pastells, Historia de la Compañía de Jesús en la Provincia del Paraguay. (Argentina, Paraguay, Uruguay, Perú, Bolivia y Brasil, según los documentos originales del Archivo General de Indias). Tomo VI (1725-1731). (Madrid 1946), pp. 477-479; AGN. Sala VII. Colección Andrés Lamas. Leg. № 2609. "Información y certificación acerca de varios puntos pertenecientes a los Indios Guaranís mandadas hacer por el Padre Jaime de Aguilar ... (02.XII.1735). f.34v; f. 35v-f. 37; f. 38v-f. 39; Pedro Lozano, Historia de la conquista de las provincias del Río de la Plata, Paraguay y Tucumán. [1745], Tomo I. (Buenos Aires 2010), pp. 665-666 y 678; y Arno Álvarez Kern, Missoes. Uma utopia política (Porto Alegre 1982), p. 197. 


\begin{tabular}{l|l|l|l}
\hline Año & $\begin{array}{l}\text { Número de guaraníes } \\
\text { Movilizados }\end{array}$ & Indios atacantes & Lugar de destino \\
\hline 1641 & 200 o $230^{65}$ & Caracarás y otros & Corrientes \\
\hline 1652 & N/E & Ningunos & $\begin{array}{l}\text { Santa Lucía } \\
\text { (reedificar Iglesia) }\end{array}$ \\
\hline 1655 & N/E & $\begin{array}{l}\text { Hometes, frentones y } \\
\text { lagunas }\end{array}$ & Corrientes \\
\hline $1657-1658$ & $\begin{array}{l}\text { (N/E N } \text { de } \\
\text { embarcaciones) }\end{array}$ & Ningunos & \\
\hline 1658 & $\begin{array}{l}\text { (N/E N }{ }^{\circ} \text { de } \\
\text { embarcaciones) }\end{array}$ & Ningunos & $\begin{array}{l}\text { Corrientes para viajar } \\
\text { a Buenos Aires }\end{array}$ \\
\hline 1673 & N/E (4 embarcaciones) & Indios "fronterizos" & $\begin{array}{l}\text { Corrientes para viajar } \\
\text { a Buenos Aires }\end{array}$ \\
\hline 1721 & 163 en 8 chalupas & Payaguás & Corrientes \\
\hline
\end{tabular}

Esta tabla expone que las primeras movilizaciones a Corrientes coinciden con el periodo de ataques de los bandeirantes del Brasil a las reducciones (1632-1641). Esto refleja que las milicias guaraníes antes de ser reconocidas por la corona como tales, comenzaron a participar en la defensa de las ciudades del nordeste rioplatense. Esto expone que la protección armada de esta frontera funcionó de manera descentralizada, recayendo en manos de indios armados su defensa. Esa primera movilización fue en el año 1637, cuando cinco canoas, doscientos treinta guaraníes y cien españoles al mando de Cristóbal Garay de Saavedra ${ }^{69}$, se dirigieron a defender Corrientes

${ }^{65}$ Según el Memorial del padre Herrán que consultamos fueron 200 indios de las reducciones, pero la Relación anónima del siglo XVIII menciona 230 indios movilizados, con la particularidad que en el documento el número 3 está remarcado sobre un 6 anterior, lo cual puede significar un número mayor de guaranies movilizados.

${ }^{66}$ Nos basamos en el Informe del padre Aguilar. Sin embargo, en la Relación anónima del siglo XVIII dice que las milicias guaraníes se enfrentaron a los "Frentones y otros indios de la ciudad de Corrientes". Esto indicaría la posibilidad de una revuelta interna de indios urbanos. No hemos hallado hasta el momento otras referencias a un movimiento de este tipo en Corrientes.

${ }^{67}$ En este caso las reducciones colaboran con embarcaciones para movilizar una capitanía de soldados desde la ciudad de Corrientes hacia Buenos Aires para defender dicha plaza de amenaza extranjera, sin mencionarla.

${ }^{68}$ Idem.

${ }^{69}$ Las movilizaciones de estas milicias fueron comandadas por cabos y oficiales españoles, “... porque de su cosecha los indios no saben delinear un ejército, ordenar los escuadrones, dividir las compañías, acomodar los soldados ni acometer con orden de milicia; sólo a montón pelean cargando con suma gritería sobre el enemigo ...”. Francisco Jarque/Diego F. Altamirano, Las misiones jesuiticas en 1687 (Buenos Aires 2008), p. 63. 
y su cercano pueblo de indios llamado Santa Lucía, del ataque de algunos nativos (caracarás, cupesalos y mepenes). Estas tropas lograron hacer retroceder a los indios a sus guaridas del Iberá ${ }^{70}$, de las que no salieron por algunos años según la documentación ${ }^{71}$. Posteriormente, se organizó una entrada a dicha región para el castigo de los rebeldes, y en ella se "... apresaron una canoa con dos indios apóstatas de la reducción de Itatí, quienes con otros de su pueblo se habían también coligado con los rebeldes ..."72. Nuevamente se expone la capacidad de los grupos de nativos para establecer alianzas o cambiar de bando según las conveniencias. Por ello las categorías de indios amigos e indios infieles se vuelven imprecisas para este tipo de frontera. $\mathrm{Al}$ año siguiente, se produce el momento de mayor enfrentamiento entre las reducciones jesuíticas con los lusitanos en la frontera oriental. Para 1638 los bandeirantes habían provocado la destrucción de muchas misiones y la emigración de algunas hacia los ríos Paraná y Paraguay. En ese año los portugueses trataban de avanzar sobre los nuevos asentamientos. Por su parte los jesuitas buscaron lograr el apoyo de las ciudades del Nordeste rioplatense para poder hacer frente a esos ataques.

Corrientes se encontraba alejada del foco de conflicto, pero los jesuitas intentaron el apoyo de sus autoridades solicitándoles el envío de tropas armadas. Posiblemente como contraprestación a los servicios que hicieron los indios de las reducciones en los años precedentes. Sin embargo la posición de las autoridades de Corrientes fue contradictoria. En primera instancia, se designaron hombres para su envío a dichas tierras; pero luego se negó definitivamente el envío de ayuda.

Los motivos del cambio de opinión y las negociaciones entre ambas partes no se conservaron. Lo que sí aparece es el posible argumento para la negativa definitiva en el envío de hombres, en palabras del procurador general de Corrientes, Juan de Lencinas a los miembros del Cabildo, el 11.I.1638:

“... requiriesen y exortasen al gen.1 Don P.o Davila Henrriquez no diese el dho socorro por estar esta tierra tan falta de el y que casso q se ubiese de dar avian de ser mas de dossientos hombres p.a poder resistir algo de la mucha fuerza que trae el enemigo [...] Los apercibidos para el dicho viaje q son quince hombres pobres sin armas ni cavallos monisiones ni pertrechoz para la dha guerra y mas para hir contra tantos y tan buenos arcabuceros como son los mamelucos y portuguesez soldados de toda la vida exersitados en ese ministerio ..."73

${ }^{70}$ Los Esteros del Iberá fueron un límite natural entre la expansión de la colonización de Corrientes y las misiones jesuíticas a orillas del río Uruguay, véase el mapa 1.

${ }^{71}$ Manuel F. Mantilla, Crónica histórica (nota 13), p. 65.

${ }^{72}$ Pedro Lozano, Historia de la conquista (nota 64), p. 666.

${ }^{73}$ Academia Nacional de la Historia, Actas Capitulares (nota 14), pp. 392-393. 
La movilización de tropas desde Corrientes nunca llegó a auxiliar a las misiones guaraníes frente a los portugueses. Posiblemente aquí también haya influido la negativa de los milicianos de Corrientes a movilizarse de sus tierras durante un prolongado tiempo. Como consecuencia de ello, los envíos de milicias guaraníes se modificaron pasando a ser sólo apoyos logísticos (principalmente embarcaciones) para Corrientes.

Solamente fueron indios armados a Corrientes (1721) cuando se dieron dos circunstancias: Por una parte, ya estaban los jesuitas asentados en la ciudad con un colegio y haciendas, teniendo por ello mayores intereses en la seguridad de Corrientes ${ }^{74}$. Y por otro lado, porque los ataques de los payaguás entre 1720 y 1722 afectaron tanto a Corrientes como a Asunción. Esta última era una ciudad importante en la política y economía jesuítica en la región, y por tanto debían defenderla.

Por todo esto, comparativamente se puede afirmar por la documentación analizada, que las acciones de las milicias guaraníes en Corrientes son escasas, en relación a las ayudas que enviaron a otras ciudades del Nordeste rioplatense como Asunción y Buenos Aires. Pero esto no significa que no tuvieran gran importancia para esta pequeña ciudad que tenía grandes problemas para lograr movilizar los recursos suficientes para defenderse de los indios del Chaco.

\section{Algunas consideraciones finales}

La ciudad de Corrientes se desarrolló en el marco de una frontera periférica del imperio hispánico. Las posibilidades de supervivencia en esos territorios dependieron de la capacidad de sus protagonistas para negociar la defensa de la frontera.

Vecinos y habitantes de Corrientes participaron activamente en las milicias urbanas a fines de reforzar lazos de jerarquía y status social. Además ciertas campañas les permitían obtener reconocimientos militares y/o mano de obra indígena. Pero sus actividades agro-ganaderas, su vivienda casi permanente en las chacras que rodeaban al núcleo urbano y su precaria economía, les impidieron participar en campañas prolongadas. Por tal motivo las movilizaciones a lejanos territorios o los turnos de guardia en fuertes durante varios meses, generaron resistencias y el fracaso de las negociaciones.

${ }^{74}$ La fundación del colegio jesuítico de Corrientes fue a finales del siglo XVII, y tuvo un valor estratégico comercial y defensivo importante al estar situado cercano a la orilla del río Paraná. Logrando participar tanto del comercio fluvial como de la defensa de la ciudad de los posibles ataques de indígenas chaqueños. 
Los grupos de indios cercanos también tuvieron una activa participación en esta frontera. La negociación les permitió obtener nuevos productos e incluso mejorar su armamento para desarrollar futuros ataques, tanto a Corrientes como a la ciudad de Asunción. Otros grupos de nativos lograron ser encomendados o reducidos, pero ello no significó que perdieran autonomía en sus decisiones. Tal es el caso de indios de Itatí participando en unos ataques de indios del Chaco al pueblo de Santa Lucía, demostrando no sólo la movilidad de estos indios en la región sino que también las categorías de indios amigos e indios infieles eran muy difusas en esta frontera.

Las autoridades de Corrientes debieron buscar nuevas alternativas para la defensa de su ciudad en determinadas situaciones. Fue así que las milicias guaraníes de las reducciones arriban a Corrientes en determinados momentos de los siglos XVII y XVIII.

Estas milicias guaraníes se configuraron para defender la frontera frente al avance del portugués, pero su capacidad de movilizar un buen número de nativos, junto al perfeccionamiento en sus tácticas y técnicas militares hicieron que pronto fueran llevadas a defender otros ámbitos geográficos. Fue en Corrientes una de las primeras y más significativas intervenciones (1637-1638) frente a los nativos de la región, inclusive procediendo a perseguirlos hasta sus guaridas en los Esteros del Iberá. La negativa de los correntinos a auxiliar a las reducciones en su lucha con los avances portugueses, significó que la política de los jesuitas para con Corrientes se modificara. La ayuda llegaría desde entonces sólo de forma logística (embarcaciones).

Sólo en el siglo XVIII volverían las milicias guaraníes a participar en Corrientes de forma activa contra los payaguás. Debiéndose este cambio en la política de los jesuitas a que sus propios intereses se vieron afectados con dichos ataques, ya tenían un colegio en Corrientes, y además los mismos afectaban a Asunción, ciudad clave en la política y el comercio de la orden en el Nordeste.

Este microcosmos analizado permite exponer cómo se dieron las negociaciones entre los protagonistas de esta frontera. Nativos, habitantes y vecinos de Corrientes, jesuitas y autoridades, participaron activamente en esta defensa de una u otra forma. Pero especialmente este caso nos permitió establecer conexiones entre la frontera chaqueña y otros ámbitos americanos, dado que las dinámicas y estrategias fronterizas fueron semejantes. Además desde nuestra perspectiva comenzamos a entender mejor estas áreas poblacionales que la mayor parte de la historiografía analizó de forma pormenorizada, pero desconectándolas entre sí. Las movilizaciones de las milicias guaraníes nos permiten erigirlas en un hilo conductor entre esos espacios aparentemente diferentes. 
La negociación entre corona, pobladores y nativos debió operar correctamente para lograr perdurar en cada uno de dichos territorios. Se observa así como el fortalecimiento del Estado moderno no se debió tanto a los progresos institucionales, mejoras administrativas o la aplicación de la fuerza, como a la respuesta interesada de los dirigentes locales ${ }^{75}$. Alcanzando la monarquía a descentralizar la defensa y sus recursos en este tipo de fronteras, dejando incluso en manos de indios armados la protección de esos territorios. Así los conceptos de centro y periferia, permiten no sólo entender desde otra perspectiva la vinculación entre metrópolis y sus colonias en cuanto a la defensa de fronteras sino también las relaciones internas dentro de esas colonias para lograr dicha defensa ${ }^{76}$.

Por todo ello, analizar la defensa de Corrientes frente a los nativos chaqueños en los siglos XVII y XVIII, significa observar la compleja negociación entre autoridades, milicias locales, nativos y jesuitas en un territorio de frontera, en una "periphery of the periphery". Los intereses posibilitaban el funcionamiento de esa defensa de la ciudad. Se apoyaba en fuerzas locales (milicias urbanas), en milicias de las reducciones guaraníes e incluso en indios auxiliares o amigos; se optaba por una política ofensiva (entradas) y/o una política defensiva (construcción de fuertes). Todo ello según los intereses de los protagonistas de esta lejana frontera.

\footnotetext{
${ }^{75}$ Véase Xavier Gil Pujol, "Centralismo e Localismo?" (nota 5), p. 127.

${ }^{76}$ Bushnell/Greene, "Peripheries" (nota 3), p. 7.
} 